\title{
A comparison of nonspecific and nictitating membrane conditioned responses: Additional support for two-factor theories
}

\author{
ROBERT C. LENNARTZ and NORMAN M. WEINBERGER \\ University of California, Irvine, California
}

\begin{abstract}
Our review of the Pavlovian defensive conditioning literature (Lennartz \& Weinberger, 1992) was presented as support for two-factor theories and demonstrated a bimodal distribution of acquisition rates. "Nonspecific" responses (e.g., heart rate changes or conditioned suppression) condition more rapidly than do "specific" responses (e.g., nictitating membrane). However, Kehoe and Macrae (this issue) have argued that the acquisition rate of nictitating membrane (NM) conditioned responses is inversely related to the number of trials per day, and that our survey included, almost exclusively, NM studies with a relatively large number of daily trials. We reanalyzed the data to eliminate this (unintended) bias. The results show that even with very few trials per day, NM conditioned responses are more slowly acquired than is conditioned suppression. We also address other issues raised by Kehoe and Macrae, such as the distinction between associative systems and peripheral responses, and other investigators' views on two-factor theories.
\end{abstract}

Kehoe and Macrae (this issue) have provided a critique of our survey of learning rates in nine response systems during Pavlovian defensive conditioning (Lennartz \& Weinberger, 1992). This survey was motivated by theoretical accounts that viewed such conditioning as being comprised of two factors, based to a considerable extent on the observation of behavioral conditioned responses (e.g., Konorski, 1967; Mowrer, 1947; Schlosberg, 1937). More specifically, theorists had pointed out that (1) within a single training situation, animals develop CRs in more than one effector system, (2) the characteristics of the CRs allowed them to be grouped into two categories, and (3) the rate of development of certain CRs was sequential. We thought it worthwhile to address this last point to determine whether experimental findings either supported or failed to support such theories.

In the title of their critique, Kehoe and Macrae attribute a two-factor theory to us; however, our efforts were confined to an examination of the literature with respect to extant two-factor theories. The only near-theoretical point we made was one of terminology. We reiterated a suggestion (Weinberger, 1982) that the more neutral description of two types of CRs as "nonspecific" and "specific," noted but not emphasized by Konorski (1967), is currently preferable to functional distinctions such as Konorski's "preparatory" and "consummatory" CRs, respectively.

\footnotetext{
This research was supported by the National Institute of Mental Health (MH 14599 and MH 09600), the National Science Foundation (BNS 83-17940, to N.M.W.), the Office of Naval Research (N00014-84-K0391, N00014-87-K-0433, and N00014-91-J-1193, all to N.M.W.), and The Monsanto Corporation. We thank Jacquie Weinberger for her secretarial assistance. R. C. Lennartz is now at the Department of Psychology, University of Virginia, Charlottesville, VA 22903.
}

The survey revealed a bimodal distribution of trials to the first consistent conditioned response (CR). Six systems rapidly exhibited initial CRs, averaging 2.7 to 8.4 trials: galvanic skin response (GSR), conditioned suppression (actually a response measure, not an effector system), blood pressure, respiration, and pupillomotor and heart rate. Three systems yielded CRs more slowly, averaging 59.2 to 95.2 trials: nictitating membrane (NM), flexion, and eyelid. This dichotomy was present within subjects as well as across subjects.

We examined the following parameters and found that they could not explain the differences in the number of trials to the first consistent CR: CS intensity, US intensity, interstimulus interval (ISI), and intertrial interval. We also pointed out that two-factor theorists had distinguished the "fast" and "slow" CRs by other criteria: (1) in any single conditioning situation, many fast CRs develop, but only one slow CR develops; and (2) the fast CRs are not specific to the nature and locus of the unconditioned stimulus (US), whereas the slow CR is very specific and generally localized to the site of application of the US. We concluded that the findings supported twostage theories of Pavlovian defensive conditioning and were compatible with an interpretation that fast CRs indexed the development of a CS-US association and that the slow CR revealed the development of a CS-CR association.

Kehoe and Macrae have contributed to this issue by opposing our conclusions, with specific points mentioned below.

1. They argue that our analysis of data from the studies of the NM CR cannot be used to support the bimodal distribution of learning rates because the rate of NM conditioning is an inverse function of the number of training trials per day; therefore, it can be fast or slow. 
2. Nonetheless, they agreed that defensive conditioning could not be explained by one factor, but criticized us for implying that two factors might be sufficient. Related to this point, they claimed that we equated peripheral responses with theoretical associative processes.

3. They also cited leading investigators (Thompson et al., 1987; Wagner \& Brandon, 1989) in support of their position.

We consider these points in turn.

\section{RAPID CONDITIONING OF THE NM CR}

The argument that the NM data cannot be used to support two-factor theory involves two questions. First, does our average value for the rate of NM acquisition accurately represent the rate of NM conditioning? Second, if not, is the rate of NM conditioning as fast as that of the alleged "fast" CRs?

\section{Averaging Across Trials per Session}

Regarding the first question, Kehoe and Macrae pointed out that the rate of acquisition of the NM CR is inversely related to the number of training trials in a session-the fewer the trials, the faster the learning. At the limit of one trial per session, the mean is 7.2 trials to the first NM CR, which is close to the grand mean of 5.7 trials that we reported for the fast CRs. We failed to take into account trials per session, and averaged across studies that differed in this variable. Accordingly, our average value for the NM CR (59.2 trials) was an inaccurate portrayal of its rate of acquisition.

We agree that Kehoe and Macrae are correct to criticize our neglect of the parameter of trials per session. The seven papers that they cite (Kehoe, Cool, \& Gormezano, 1991; Kehoe \& Gormezano, 1974; Levinthal, 1973; Levinthal \& Papsdorf, 1970; Levinthal, Tartell, Margolin, \& Fishman, 1985; Salafia, Daston, \& Martino, 1976; Salafia, Terry, \& Daston, 1975) demonstrate that the NM CR can be acquired in considerably fewer trials than is usually reported (mean of 59.2 trials in our survey). With regard to those seven NM papers, we want to emphasize that we did not deliberately attempt to ignore these very interesting data. Two of the seven (Salafia et al., 1976; Salafia et al., 1975) did not report trials to the 1st CR, but did report trials to the 20th CR, and therefore could not be used in the survey. Two of the remaining five (Kehoe et al., 1991; Levinthal et al., 1985) were published either past our 1985 cutoff date, or in that very year; thus, our quota of 10-15 papers per response system (Lennartz \& Weinberger, 1992, p. 97) had been attained. Of the remaining three, one (Kehoe \& Gormezano, 1974) was included in the survey; we simply missed the two earliest papers (Levinthal \& Papsdorf, 1970, and Levinthal, 1973). In any event, Kehoe and Macrae are quite correct that the average value that we calculated for the NM CR is not valid.

\section{How Rapidly Does the NM CR Develop?}

The second question concerns whether the NM CR develops as rapidly as do the fast CRs. In our discussion of the larger mean value for slow versus fast CRs, we made the following statement in a footnote:

These findings do not imply that the slow responses cannot develop much more rapidly than the values reported in this survey. For example, the use of extremely long ITIs of 24 or $48 \mathrm{~h}$ (rarely employed in conditioning studies) results in the NM CR in 5-10 trials (Levinthal, Tartell, Margolin, \& Fishman, 1985). It is the relative rates of development of the "fast" and "slow" responses which are at issue [italics added]. Thus, in the case of rapid development of the NM CR, the question is whether or not, for example, the cardiac CR still develops before the NM response develops. (Lennartz \& Weinberger, 1992, p. 114)

Kehoe and Macrae provide a mean value of 7.2 trials to the first NM CR at the optimal rate of one trial per session, compared with the "grand mean of 5.7 trials reported for nonspecific responses." However, the NM data cited by Kehoe and Macrae have a large variance at one trial per session, as is shown in their Figure 1. More specifically, the data fall into two groups: those reported by Levinthal and co-workers versus those reported by $\mathrm{Ke}$ hoe and co-workers. The mean for the former is 5.0 trials, and the mean for the latter is 17.0 trials. This difference is statistically significant (see Table 1). The slower rate for the Kehoe studies might be related to the fact that, as a group, they used a less intense CS than did Levinthal (85.6 vs. $93.0 \mathrm{~dB}$, respectively; however, compare Kehoe \& Gormezano, 1974, with Levinthal, 1973, for groups with comparable CS intensity and other parameters but different learning rates). In view of the significant difference in learning rates between the two laboratories, combining the two sources of data into a single mean value of 7.2 trials to the first NM CR may be misleading.

In view of this situation, it would be premature to accept the mean of 7.2 trials for the NM response until the matter is clarified. In short, although trials to the first CR

Table 1

NM Conditioning Data of Levinthal and Kehoe, One Trial per Session

\begin{tabular}{|c|c|c|c|c|c|c|c|}
\hline \multirow[b]{2}{*}{ Variable } & \multicolumn{3}{|c|}{ Levinthal } & \multicolumn{3}{|c|}{ Kehoe } & \multirow{2}{*}{$\begin{array}{c}\text { Comparison } \\
(t \text { tests })\end{array}$} \\
\hline & $M$ & $S E$ & $N$ & $M$ & $S E$ & $N$ & \\
\hline $\begin{array}{l}\text { No. of trials } \\
\text { to first } C R\end{array}$ & 5.0 & 0.72 & 14 & 17.0 & 1.9 & 5 & $p \leq .000$ \\
\hline $\begin{array}{l}\text { CS intensity } \\
\text { (decibels) }\end{array}$ & 93.0 & 0 & 14 & 85.6 & 1.6 & 5 & $p \leq .0001$ \\
\hline $\begin{array}{l}\text { US intensity } \\
\text { (mcoulombs) }\end{array}$ & 0.26 & 0.005 & 14 & 0.27 & 0.03 & 5 & n.s. \\
\hline ISI (se & 0.99 & 0.18 & 14 & 1.3 & 0.53 & 5 & n.s. \\
\hline Trials/session & 1.0 & 0 & 14 & 1.0 & 0 & 5 & n.s. \\
\hline $\begin{array}{l}\text { Trials/block } \\
\text { (graph) }\end{array}$ & 2.4 & 0.36 & 14 & 5.0 & 0 & 5 & $p \leq .0006$ \\
\hline
\end{tabular}


is affected by the number of trials per training session, the literature does not yet provide general agreement concerning how rapidly the NM CR develops. Given the issues raised by Kehoe and Macrae, this problem seems to be sufficiently important that it should be resolved in the near future. It will also be important to understand the effects of trials per session on cardinal features of the NM CR, such as change in optimal ISI from brief to longer intervals (e.g., 250-1,250 msec) as the number of trials per session declines to one per session (Levinthal, 1973; Levinthal \& Papsdorf, 1970).

\section{COMPARISON OF RESPONSE SYSTEMS FOR ONE TO FIVE TRIALS PER SESSION}

Kehoe and Macrae have considered several alternatives for analyzing the data of our survey, which would eliminate the bias of averaging across studies with different numbers of trials per training session: (1) fastest reliable rate for each response system, (2) number of sessions instead of number of trials to first CR, and (3) within-subject comparisons for multiple response systems. They conclude that none of these approaches alters their conclusion that the NM CR can develop as fast as the nonspecific responses, given one training trial per session.

However, following their lead, we have considered other ways to make use of the data in the survey in order to help resolve the issue. The results indicate that even under the most optimal circumstances for conditioning of the NM CR, but not necessarily optimal circumstances for conditioning of nonspecific CRs, a significant difference in rate of conditioning still can be found.

\section{Rates of Acquisition at Five or Fewer Trials per Session}

We reanalyzed the survey data to optimize the rate of acquisition for the NM CR. We also made certain to include the five out of seven papers cited by Kehoe and Macrae that met the selection criteria of the survey (Lennartz \& Weinberger, 1992, pp. 97-98). Specifically, we determined the number of trials per session for every study and then confined our initial reanalysis to data that had five or fewer trials per session. We further limited this analysis to findings for which data were plotted in blocks of five trials or fewer; this restriction was intended to prevent any large trial blocks from yielding apparent slow rates of acquisition.

As described in our earlier paper (Lennartz \& Weinberger, 1992), the first CR was determined to occur when the response was greater than that of the control (unpaired CSs and USs, for example) group, and remained so. NM studies often do not include control groups; in these cases a pseudoconditioning baseline of about $10 \%$ was assumed.

The results are shown in Table 2. There are $5 \mathrm{NM}$ papers (with 22 groups), 1 flexion paper (8 groups), 1 GSR paper ( 2 groups), and 10 conditioned suppression papers (26 groups).

First, we compared the 30 groups from the NM and flexion papers (slow CRs) with the 28 groups from the
GSR and suppression papers (fast CRs) on the same variables used for the survey, adding two additional analyses-trials per session and the number of trials per block in the learning plots.

The results are presented in Table 3 . Trials to the first CR is significantly smaller for the fast CRs than for the slow CRs (3.8 vs. 8.2 trials, respectively). However, four of the other five variables are also significantly different between the two groups. For CS intensity we limited the analysis to the auditory CSs, which were most common for each group, as done originally (Lennartz \& Weinberger, 1992). Thus, for the flexion CR we used only the tone CSs, and for the conditioned suppression we used only the white-noise CSs. (All of the flexion groups had a tone CS; the two GSR groups had light CSs.) CS intensity is significantly greater for the slow CRs $(85.6 \mathrm{~dB}$ vs. $76.8 \mathrm{~dB}$ for the fast responses). However, this should favor the slow CRs, as more intense CSs support better conditioning (as reviewed in Mackintosh, 1974). ISI is also significantly different; the value for the slow CRs $(0.98 \mathrm{sec})$ is more optimal for such discrete responses than is the value for the fast CRs $(93.2 \mathrm{sec})$, so this should not explain fewer trials to acquisition criteria for the fast CRs.

Trials per block was significantly greater for the more slowly acquired CRs. The argument could be made that this could artificially increase the estimated values to first $\mathrm{CR}$, because we used the midpoint of the block for the values. This difference is largely due to the eight NM groups with data plotted in trial blocks of five. However, in seven of the groups, the first CR did not appear until at least the third block (and in half of the groups it did not appear until the fourth block, or later). Thus, it would be difficult to argue that the difference in trials to first CR was an artifact of the plotting procedure.

US intensity was greater for the fast CRs, which favors their acquisition (Mackintosh, 1974). This issue will be addressed in a later analysis.

It should be noted that in this sample, the majority of the "slow" system studies are NM, and the majority of "fast" studies are of conditioned suppression. To allow for a more direct comparison of these two systems, the data were reanalyzed with the NM and conditioned suppression papers only. The findings are summarized in Table $4 \mathrm{~A}$, which shows that the number of trials to the first $\mathrm{CR}$ is significantly higher for the NM than for the conditioned suppression studies ( 9.3 vs. 3.9 , respectively). CS intensity, US intensity, and ISI are still significantly different between the two groups. Furthermore, trials per session is significant, although this value is lower for the NM papers (1.5 vs. 2.8 ), and thus should favor them, according to the work cited by Kehoe and Macrae.

Of the variables that differ between the two groupsother than trials to first CR-US intensity was the most likely to be an alternate explanation for the difference in acquisition rate. Therefore, the data from Table 4A were matched on US intensity, which resulted in $12 \mathrm{NM}$ and 12 conditioned suppression groups. The results of this analysis are provided in Table 4B. 
Table 2

Classical Defensive Conditioning Studies With Five or Fewer Trials per Session, and Plotted in Five or Fewer Trials per Block

\begin{tabular}{|c|c|c|c|c|c|c|c|c|}
\hline Response & $\begin{array}{c}\text { First CR } \\
\text { (No. of Trials) }\end{array}$ & $\begin{array}{c}\text { CS } \\
\text { Intensity } \\
\text { (decibels) }\end{array}$ & $\begin{array}{c}\text { US } \\
\text { Duration } \\
\text { (seconds) }\end{array}$ & $\begin{array}{c}\text { US } \\
\text { Intensity } \\
\text { (milliamps) }\end{array}$ & $\begin{array}{c}\text { ISI } \\
\text { (seconds) }\end{array}$ & $\begin{array}{c}\text { Trials per } \\
\text { Session }\end{array}$ & $\begin{array}{l}\text { Plotted } \\
\text { Trials per } \\
\text { Block }\end{array}$ & Citation \\
\hline FLEX & $2-4$ & $80(T)$ & 0.100 & 1.70 & 0.900 & 4 & 4 & Barnes (1956) \\
\hline FLEX & $2-4$ & $80(\mathrm{~T})$ & 0.100 & 1.70 & 0.900 & 4 & 4 & $" \quad "$ \\
\hline FLEX & $2-4$ & $80(\mathrm{~T})$ & 0.100 & 1.70 & 0.900 & 4 & 4 & $"$ \\
\hline FLEX & $2-4$ & $80(\mathrm{~T})$ & 0.100 & 1.70 & 0.900 & 4 & 4 & $"$ \\
\hline FLEX & $5-8$ & $60(\mathrm{~T})$ & 0.100 & 1.70 & 0.900 & 4 & 4 & $"$ \\
\hline FLEX & $2-4$ & $60(\mathrm{~T})$ & 0.100 & 1.70 & 0.900 & 4 & 4 & $"$ \\
\hline FLEX & $5-8$ & $60(T)$ & 0.100 & 1.70 & 0.900 & 4 & 4 & $"$ \\
\hline FLEX & $13-16$ & $60(T)$ & 0.100 & 1.70 & 0.900 & 4 & 4 & $"$ \\
\hline GSR & 2 & $?(\mathrm{~L})$ & 0.100 & 4.30 & 4.900 & 5 & 1 & Kimmel et al. (1969) \\
\hline GSR & 2 & $?(\mathrm{~L})$ & 0.100 & 8.60 & 4.900 & 5 & 1 & " $"$ \\
\hline NM & 2 & $93(\mathrm{~T})$ & 0.100 & 3.00 & 1.250 & 1 & 1 & Levinthal \& Papsdorf (1970) \\
\hline NM & 6 & $93(\mathrm{~T})$ & 0.100 & 3.00 & 0.250 & 1 & 1 & $"$ \\
\hline $\mathrm{NM}$ & 2 & $93(\mathrm{~T})$ & 0.100 & 2.50 & 1.250 & 1 & 1 & Levinthal (1973) \\
\hline NM & 4 & $93(\mathrm{~T})$ & 0.100 & 2.50 & 0.250 & 1 & 1 & $"$ \\
\hline NM & $11-15$ & $93(\mathrm{~T})$ & 0.100 & 2.50 & 0.250 & 5 & 5 & $"$ \\
\hline NM & $6-10$ & $93(\mathrm{~T})$ & 0.100 & 2.50 & 1.250 & 5 & 5 & $"$ \\
\hline NM & 8 & $93(\mathrm{~T})$ & 0.100 & 2.50 & 0.250 & 1 & 1 & $"$ \\
\hline NM & 3 & $93(\mathrm{~T})$ & 0.100 & 2.50 & 1.250 & 1 & 1 & $"$ \\
\hline NM & $11-15$ & $92(\mathrm{~T})$ & 0.050 & 3.00 & 0.400 & 1 & 5 & Kehoe \& Gormezano (1974) \\
\hline NM & $26-30$ & $92(\mathrm{~T})$ & 0.050 & 3.00 & 0.400 & 5 & 5 & " \\
\hline NM & $7-9$ & $93(\mathrm{~T})$ & 0.100 & 2.50 & 0.200 & 1 & 3 & Levinthal et al. (1985) \\
\hline NM & $7-9$ & $93(\mathrm{~T})$ & 0.100 & 2.50 & 0.500 & 1 & 3 & $"$ \\
\hline NM & $4-6$ & $93(\mathrm{~T})$ & 0.100 & 2.50 & 0.800 & 1 & 3 & $"$ \\
\hline NM & $4-6$ & $93(\mathrm{~T})$ & 0.100 & 2.50 & 1.100 & 1 & 3 & $"$ \\
\hline NM & $2-4$ & $93(\mathrm{~T})$ & 0.100 & 2.50 & 1.200 & 1 & 4 & $"$ \\
\hline NM & $2-4$ & $93(\mathrm{~T})$ & 0.100 & 2.50 & 2.200 & 1 & 4 & $"$ \\
\hline NM & $9-12$ & $93(\mathrm{~T})$ & 0.100 & 2.50 & 1.200 & 1 & 4 & $"$ \\
\hline NM & $2-4$ & $93(\mathrm{~T})$ & 0.100 & 2.50 & 2.200 & 1 & 4 & $"$ \\
\hline NM & $21-25$ & $84(\mathrm{~T})$ & 0.100 & 3.00 & 0.400 & 1 & 5 & Kehoe et al. (1991) \\
\hline NM & $16-20$ & $84(\mathrm{~T})$ & 0.100 & 3.00 & 0.800 & 1 & 5 & $"$ \\
\hline NM & $16-20$ & $84(T)$ & 0.100 & 3.00 & 1.600 & 1 & 5 & $"$ \\
\hline NM & $11-15$ & $84(\mathrm{~T})$ & 0.100 & 3.00 & 3.200 & 1 & 5 & $"$ \\
\hline SUPP & $9-12$ & $70(\mathrm{WN})$ & 0.500 & 0.49 & 180 & 4 & 4 & Annau \& Kamin (1961) \\
\hline SUPP & $2-4$ & $70(\mathrm{WN})$ & 0.500 & 0.85 & 180 & 4 & 4 & $" \quad "$ \\
\hline SUPP & $5-8$ & $70(\mathrm{WN})$ & 0.500 & 1.55 & 180 & 4 & 4 & $"$ \\
\hline SUPP & $2-4$ & $70(\mathrm{WN})$ & 0.500 & 2.91 & 180 & 4 & 4 & $"$ \\
\hline SUPP & $5-8$ & $70(\mathrm{WN})$ & 0.500 & $\sim 0.72$ & 180 & 4 & 4 & Kamin (1961) \\
\hline SUPP & $5-8$ & $70(\mathrm{WN})$ & 0.500 & $\sim 0.85$ & 180 & 4 & 4 & $" \quad "$ \\
\hline SUPP & $5-8$ & $69(\mathrm{WN})$ & 0.500 & 0.85 & 180 & 4 & 4 & Kamin (1963) \\
\hline SUPP & 2 & $82(\mathrm{WN})$ & 0.500 & 0.80 & 25.5 & 1 & 1 & Burdick \& James (1973) \\
\hline SUPP & $2-3$ & $82(\mathrm{WN})$ & 0.500 & 0.10 & 25.5 & 1 & 1 & James et al. (1973) \\
\hline SUPP & $2-3$ & $82(\mathrm{WN})$ & 0.500 & 0.50 & 25.5 & 1 & 1 & $" \prime$ \\
\hline SUPP & $2-3$ & $82(\mathrm{WN})$ & 0.500 & 1.00 & 25.5 & 1 & 1 & $"$ \\
\hline SUPP & $2-3$ & $82(\mathrm{WN})$ & 0.500 & 2.00 & 25.5 & 1 & 1 & $"$ \\
\hline SUPP & $2-3$ & $82(\mathrm{WN})$ & 0.500 & 0.10 & 25.5 & 2 & 2 & $"$ \\
\hline SUPP & $2-3$ & $82(\mathrm{WN})$ & 0.500 & 0.50 & 25.5 & 2 & 2 & $"$ \\
\hline SUPP & $2-3$ & $82(\mathrm{WN})$ & 0.500 & 1.00 & 25.5 & 2 & 2 & $"$ \\
\hline SUPP & $2-3$ & $82(\mathrm{WN})$ & 0.500 & 2.00 & 25.5 & 2 & 2 & $"$ \\
\hline SUPP & $4-6$ & (L) & 0.200 & 0.50 & 60 & 3 & 3 & Riess \& Farrar (1973) \\
\hline SUPP & $7-9$ & (L) & 0.500 & 0.50 & 60 & 3 & 3 & $"$ \\
\hline SUPP & $2-3$ & (L) & 1.000 & 0.50 & 60 & 3 & 3 & $"$ \\
\hline SUPP & $2-3$ & (L) & 3.000 & 0.50 & 60 & 3 & 3 & $"$ \\
\hline SUPP & 2 & $91(\mathrm{C})$ & 0.500 & 1.00 & 30 & 1 & 1 & Gustafson et al. (1975) \\
\hline SUPP & $2-4$ & $71(\mathrm{~T})$ & 1.000 & 2.00 & 120 & 4 & 4 & Logan \& Schnur (1976) \\
\hline SUPP & 3 & $80(\mathrm{WN})$ & 0.500 & 1.00 & 180 & 4 & 1 & Gray (1979) \\
\hline SUPP & 4 & $\mathrm{~L}+\mathrm{WN}$ & 0.500 & 1.00 & 180 & 4 & 1 & " " \\
\hline SUPP & 3 & $\mathrm{~L}+\mathrm{WN}$ & 0.500 & 1.00 & 180 & 4 & 1 & $"$ \\
\hline SUPP & 4 & $75(\mathrm{WN})$ & 0.800 & 1.00 & 180 & 3 & 1 & Randich \& Maixner (1981) \\
\hline
\end{tabular}

Note-FLEX = leg flexion (dog); GSR = galvanic skin response (human); NM = nictitating membrane (rabbit); SUPP = conditioned suppression (rat); $\mathrm{T}=$ tone; $\mathrm{WN}=$ white noise; $\mathrm{C}=$ clicks; $\mathrm{L}=$ light. 
Matching on US intensity eliminated not only this difference between the two groups, but also those for trials per session and trials per plotted block. CS intensity and ISI are still significantly different; but, once again, these differences should favor the NM response. Most importantly, the number of trials to the first CR is significantly larger for the NM CR (10.7 trials) than for conditioned suppression (4.8 trials). This holds even with a low number of trials per session $(M=2.0$ for NM, and $M=2.8$ for conditioned suppression).

An interim summary is that the NM response requires significantly more trials to the first CR than do the fast CRs for findings restricted to five trials or fewer per session. However, it could be argued that this analysis still places the NM response at a disadvantage, because it conditions more quickly at one trial per session than at two to five trials per session.

\section{Comparisons of Learning Rates at One Trial per Session}

We conducted a final set of analyses, restricting data from the NM response to its optimal condition of one trial per session. It will be recalled that the Levinthal and Kehoe data are significantly different at one trial per session, so this point was also addressed. The only fast CR for which sufficient data at one trial per session are available is for conditioned suppression ("Supp" in Table 2). It should be noted that whether or not one trial per session is optimal for Supp is unknown, so this comparison might favor the NM response a priori. We later address the preferred method of comparison, which is the simultaneous analysis of different types of responses within the same subject.

A comparison of Supp and NM is provided in Table 5, which combines the NM data from the Levinthal and $\mathrm{Ke}$ hoe studies, as done by Kehoe and Macrae. The mean trials are 2.3 for Supp and 8.2 for NM ( $p \leq .04)$. There are also significant differences for CS intensity and ISI, but these favor the NM response. US intensity is significantly greater for Supp, thereby clouding interpretation of the findings.

A comparison of Supp with the Kehoe et al. (1991) NM data is given in Table 6 . The mean trials are 2.3 versus

Table 3

Slow and Fast Response Systems, Trials per Session, and Trials per Block (Plots) $\leq 5$

\begin{tabular}{|c|c|c|c|c|c|c|c|}
\hline \multirow[b]{2}{*}{ Variable } & \multicolumn{3}{|c|}{ Slow } & \multicolumn{3}{|c|}{ Fast } & \multirow{2}{*}{$\begin{array}{c}\text { Comparisons } \\
(t \text { tests })\end{array}$} \\
\hline & $M$ & $S E$ & $N$ & $M$ & $S E$ & $N$ & \\
\hline $\begin{array}{l}\text { No. of trials } \\
\text { to first CR }\end{array}$ & 8.2 & 1.2 & 30 & 3.8 & 0.41 & 28 & $p \leq .002$ \\
\hline $\begin{array}{r}\text { CS intensity } \\
\text { (decibels) }\end{array}$ & 85.6 & 2.1 & 30 & 76.8 & 1.4 & 18 & $p \leq .004$ \\
\hline $\begin{array}{l}\text { US intensity } \\
\text { (mcoulombs) }\end{array}$ & 0.23 & 0.009 & 30 & 0.59 & 0.09 & 28 & $p \leq .0001$ \\
\hline ISI (seconds) & 0.98 & 0.12 & 30 & 93.2 & 14.0 & 28 & $p \leq .0001$ \\
\hline Trials/session & 2.2 & 0.30 & 30 & 3.0 & 0.25 & 28 & n.s. \\
\hline $\begin{array}{l}\text { Trials/block } \\
\text { (plot) }\end{array}$ & 3.5 & 0.26 & 30 & 2.3 & 0.25 & 28 & $p \leq .001$ \\
\hline
\end{tabular}

Table 4A

NM and Conditioned Suppression Data, Trials per Session, and Trials per Block (Plots) $\leq 5$

\begin{tabular}{ccccccccc}
\hline & \multicolumn{3}{c}{ NM } & & \multicolumn{3}{c}{ Suppression } & Comparisons \\
\cline { 2 - 3 } Variable & $M$ & $S E$ & $N$ & & $M$ & $S E$ & $N$ & $(t$ tests) \\
\hline $\begin{array}{c}\text { No. of trials } \\
\text { to first CR }\end{array}$ & 9.3 & 1.5 & 22 & 3.9 & 0.43 & 26 & $p \leq .0007$ \\
$\begin{array}{c}\text { CS intensity } \\
\text { (decibels) }\end{array}$ & 91.3 & 0.75 & 22 & 76.8 & 1.4 & 18 & $p \leq .0001$ \\
$\begin{array}{c}\text { US intensity } \\
\text { (mcoulombs) }\end{array}$ & 0.25 & 0.009 & 22 & 0.59 & 0.09 & 26 & $p \leq .002$ \\
$\begin{array}{c}\text { ISI (seconds) } \\
\text { Trials/session }\end{array}$ & 1.0 & 0.17 & 22 & 100.0 & 14.3 & 26 & $p \leq .0001$ \\
$\begin{array}{c}\text { Trials/block } \\
\text { (graph) }\end{array}$ & 3.4 & 0.30 & 22 & 2.8 & 0.24 & 26 & $p \leq .002$ \\
\hline
\end{tabular}

Table 4B

NM and Conditioned Suppression Data, Trials per Session, and Trials per Block (Plots) $\leq 5$, Matched on US Intensity

\begin{tabular}{|c|c|c|c|c|c|c|c|}
\hline \multirow[b]{2}{*}{ Variable } & \multicolumn{3}{|c|}{ NM } & \multicolumn{3}{|c|}{ Suppression } & \multirow{2}{*}{$\begin{array}{c}\text { Comparisons } \\
(t \text { tests })\end{array}$} \\
\hline & $M$ & $S E$ & $N$ & $M$ & $S E$ & $N$ & \\
\hline $\begin{array}{l}\text { No. of trials } \\
\text { to first CR }\end{array}$ & 10.7 & 2.3 & 12 & 4.8 & 0.80 & 12 & $p \leq .03$ \\
\hline $\begin{array}{l}\text { CS intensity } \\
\text { (decibels) }\end{array}$ & 91.3 & 0.99 & 12 & 75.9 & 2.0 & 10 & $p \leq .0001$ \\
\hline $\begin{array}{l}\text { US intensity } \\
\text { (mcoulombs) }\end{array}$ & 0.25 & 0.01 & 12 & 0.27 & 0.04 & 12 & 11.8. \\
\hline ISI (seconds) & 0.93 & 0.27 & 12 & 95.6 & 21.8 & 12 & $p \leq .0003$ \\
\hline Trials/session & 2.0 & 0.52 & 12 & 2.8 & 0.37 & 12 & n.s. \\
\hline $\begin{array}{l}\text { Trials/block } \\
\text { (graph) }\end{array}$ & 3.6 & 0.50 & 12 & 2.8 & 0.37 & 12 & n.s. \\
\hline
\end{tabular}

17.0 for Supp vs. NM ( $p \leq .0001)$. There is a significant difference for CS intensity and ISI, both of which favor the NM response, and no significant difference in US intensity. Therefore, Supp conditions more rapidly than does the NM response, as studied by Kehoe and coworkers at the optimal circumstance for the NM CR of one trial per session.

Finally, Supp was compared with the Levinthal NM data (Table 7). The mean values of 2.3 versus 5.0 trials, respectively, are significantly different. That is, the fastest reported NM CRs require more trials to the first CR than does conditioned suppression. There are also significant differences in CS intensity and ISI, but both favor the NM response. However, the US intensity was significantly greater for Supp, which might or might not account for the difference in rate of appearance of the first CR.

\section{US Intensity: Higher Levels of Shock Current in NM Conditioning}

The effective US intensity is a critical factor in the rate of learning, but it is not fully understood. For example, we used charge (current multiplied by time) as a measure of effective US intensity-something not routinely reported in the literature, in which current alone is usually emphasized. However, the relative importance of charge (expressed in coulombs) and current (expressed in milli- 
amps) for shock applied to the same locus in conditioning paradigms is not completely understood within the same preparation. The problems may be exacerbated for shock applied to different loci in different orders of mammal in different training situations. For example, when a shock is applied to the area of the eye of a restrained rabbit, is it more, less, or equally "effective"' as the same shock applied to the footpads of an unrestrained rat that is confined to a small box? Is shock equally effective throughout its duration? Or is the shock onset the major determinant of effective shock intensity? The list of questions could be quite lengthy.

Our analyses, presented above, show that shock level was stronger for Supp than for NM, particularly for the Levinthal et al. (1985) studies. This is based on coulombs. However, reference to Table 2 shows that shock, as indexed by current, was significantly weaker for Supp than for NM (ranges $=0.49-2.91 \mathrm{~mA}$ for Supp vs. 2.50 $3.00 \mathrm{~mA}$ for NM; for Supp, $M=0.97 \pm 0.13 \mathrm{~mA}$, and for NM, $M=2.7 \pm 0.05 \mathrm{~mA}, p \leq .0001$ ). Therefore, if one uses current as the measure of US intensity, then the NM response conditions more slowly, despite its having a higher US level and the optimal number of trials of one per session.

Table 5

Conditioned Suppression Data, and NM Data of Levinthal and Kehoe, One Trial per Session

\begin{tabular}{|c|c|c|c|c|c|c|c|}
\hline \multirow[b]{2}{*}{ Variable } & \multicolumn{3}{|c|}{ Suppression } & \multicolumn{3}{|c|}{$\begin{array}{c}\text { Levinthal \& } \\
\text { Kehoe }\end{array}$} & \multirow{2}{*}{$\begin{array}{c}\text { Comparisons } \\
(t \text { tests }) \\
\end{array}$} \\
\hline & $M$ & $S E$ & $N$ & $M$ & $S E$ & $N$ & \\
\hline $\begin{array}{l}\text { No. of trials } \\
\text { to first CR }\end{array}$ & 2.3 & 0.11 & 6 & 8.2 & 1.4 & 19 & $p \leq .04$ \\
\hline $\begin{array}{l}\text { CS intensity } \\
\text { (decibels) }\end{array}$ & 82.0 & 0 & 5 & 91.1 & 0.86 & 19 & $p \leq .0001$ \\
\hline $\begin{array}{l}\text { US intensity } \\
\text { (mcoulombs) }\end{array}$ & 0.45 & 0.13 & 6 & 0.26 & 0.008 & 19 & $p \leq .02$ \\
\hline ISI (seconds) & 26.3 & 0.75 & 6 & 1.1 & 0.18 & 19 & $p \leq .0001$ \\
\hline Trials/session & 1.0 & 0 & 6 & 1.0 & 0 & 19 & n.s. \\
\hline $\begin{array}{l}\text { Trials/block } \\
\text { (graph) }\end{array}$ & 1.0 & 0 & 6 & 3.1 & 0.37 & 19 & $p \leq .005$ \\
\hline
\end{tabular}

Table 6

Conditioned Suppression Data, and NM Data of Kehoe et al. (1991), One Trial per Session

\begin{tabular}{|c|c|c|c|c|c|c|c|}
\hline \multirow[b]{2}{*}{ Variable } & \multicolumn{3}{|c|}{ Suppression } & \multicolumn{3}{|c|}{ Kehoe et al. } & \multirow{2}{*}{$\begin{array}{c}\text { Comparisons } \\
(t \text { tests })\end{array}$} \\
\hline & $M$ & $S E$ & $N$ & $M$ & $S E$ & $N$ & \\
\hline $\begin{array}{l}\text { No. of trials } \\
\text { to first CR }\end{array}$ & 2.3 & 0.11 & 6 & 17.0 & 1.9 & 5 & $p \leq .0001$ \\
\hline $\begin{array}{l}\text { CS intensity } \\
\text { (decibels) }\end{array}$ & 82.0 & $\mathbf{0}$ & 5 & 85.6 & 1.6 & 5 & n.s. \\
\hline $\begin{array}{l}\text { US intensity } \\
\text { (mcoulombs) }\end{array}$ & 0.45 & 0.13 & 6 & 0.27 & 0.03 & 5 & n.s. \\
\hline ISI (seconds) & 26.3 & 0.75 & 6 & 1.3 & 0.53 & 5 & $p<.0001$ \\
\hline Trials/session & 1.0 & 0 & 6 & 1.0 & 0 & 5 & n.s. \\
\hline $\begin{array}{l}\text { Trials/block } \\
\text { (graph) }\end{array}$ & 1.0 & 0 & 6 & 5.0 & 0 & 5 & $p<.0001$ \\
\hline
\end{tabular}

Table 7

Conditioned Suppression Data, and NM Data of Levinthal, One Trial per Session

\begin{tabular}{ccccccccc} 
& \multicolumn{3}{c}{ Suppression } & \multicolumn{3}{c}{ Levinthal } & Comparisons \\
\cline { 2 - 6 } Variable & $M$ & $S E$ & $N$ & $M$ & $S E$ & $N$ & $(t$ tests) \\
\hline $\begin{array}{c}\text { No. of trials } \\
\text { to first CR }\end{array}$ & 2.3 & 0.11 & 6 & 5.0 & 0.72 & 14 & $p \leq .03$ \\
$\begin{array}{c}\text { CS intensity } \\
\text { (decibels) }\end{array}$ & 82.0 & 0 & 5 & 93.0 & 0 & 14 & $p \leq .0001$ \\
$\begin{array}{c}\text { US intensity } \\
\text { (mcoulombs) }\end{array}$ & 0.45 & 0.13 & 6 & 0.26 & 0.005 & 14 & $p \leq .04$ \\
$\begin{array}{c}\text { ISI (seconds) } \\
\text { Trials/session }\end{array}$ & 26.3 & 0.75 & 6 & 0.99 & 0.18 & 14 & $p \leq .0001$ \\
$\begin{array}{c}\text { Trials/block } \\
\text { (graph) }\end{array}$ & 1.0 & 0 & 6 & 1.0 & 0 & 14 & n.s. \\
\hline
\end{tabular}

\section{Summary}

In summary, although the number of trials to the first NM CR is directly related to the number of trials per session (an interesting issue beyond the scope of this paper), it does not necessarily follow that the NM CR is acquired as rapidly as are the nonspecific responses, such as conditioned suppression. For five or fewer trials per session, the NM conditions more slowly than does conditioned suppression. At one trial per session, the actual rate of conditioning of the NM differs significantly between the two laboratories that have reported such data. Under the optimal condition of one trial per session, the NM CR develops more slowly than suppression for data from Kehoe and co-workers. The data from Levinthal's laboratory also reveal slower conditioning of the NM CR, but weaker US intensity, calculated as coulombs, precludes an unambiguous interpretation of this comparison. However, the US intensity is stronger for the NM CR when expressed in current $(0.9 \pm 0.26 \mathrm{~mA}$ for Supp, and $2.6 \pm 0.05 \mathrm{~mA}$ for NM, $p \leq .0001)$. Therefore, although $\mathrm{NM}$ acquisition is faster with a reduced density of trials, it nonetheless requires more trials to reach the first consistent CR than does conditioned suppression, an example of nonspecific conditioned responses.

\section{RAPID ASSOCIATIVE CHANGES IN THE UNCONDITIONED RESPONSE}

With regard to one of the studies in which trials per session was manipulated (Kehoe et al., 1991), Kehoe and Macrae note that, "In the rabbit ... the UR shows associative changes before the first CR appears." Kehoe et al. point out that rabbits trained with one or five paired trials per session showed a 2-mm increase in the unconditioned response (UR) when the first trial is compared with subsequent trials, but before the first CR. This is larger than the increase observed in the unpaired groups. Thus, even under the optimal training conditioning for the NM-one trial per day-there is still behavioral evidence of learning before the first NM CR appears. 
The basic phenomenon of an increase in UR amplitude when it is preceded by a neutral (i.e., not yet conditioned) stimulus (i.e., "reflex facilitation") has been well reported in the rabbit NM preparation (Harvey, Gormezano, \& Cool-Hauser, 1985; Ison \& Leonard, 1971; Young, Cegavske, \& Thompson, 1976.) Although this increase is present even before conditioning trials have started, the maintenance of NM reflex facilitation has been demonstrated to involve an associative process that can occur within five trials (Weisz \& McInerney, 1990). It has been proposed that this maintenance of the reflex facilitation is an example of the first, nonspecific phase of two-factor learning theories (Weisz, Harden, \& Xiang, 1992). Moreover, modulation of such facilitation involves the amygdala (Weisz et al., 1992), suggesting that rapidly acquired conditioned fear may be indexed by associative reflex facilitation of the unconditioned NM response. ${ }^{1}$

The increase in UR reported by Kehoe et al. (1991) may be such a conditioned modification of the UR. This is, in essence, the simultaneous recording of two CRs. And, as Kehoe and Macrae themselves note, these "associative changes" in the UR appear first, before the traditional NM CRs. Therefore, the associative reflex facilitation supports the claim of two-factor theorists that Pavlovian defensive conditioning cannot be explained by recourse to a single underlying associative process.

\section{RELEVANCE OF RATES OF ACQUISITION TO TWO-FACTOR THEORIES}

If we understand Kehoe and Macrae, they view a survey of the rates of development of CRs in different response systems as largely irrelevant to two-stage theories of Pavlovian defensive conditioning. We take this meaning from the following quotation:

In two-factor theories of the type advocated by Lennartz and Weinberger, the key distinction is between two theoretical, associative systems, not two types of peripheral responses (cf. Konorski, 1967; Mowrer, 1947; Schlosberg, 1937; Schneiderman, 1972). (p. 3)

Of course, the fundamental issue concerns the number and type of associative processes rather than peripheral responses; we most definitely did not imply otherwise.

Historically, the characteristics of peripheral responses have provided an important basis for inferring the existence of different associative processes. If all CRs developed at the same rate, it is unlikely that two-factor, and particularly two-stage, theories would have developed. Two-factor theories have been based, at least, on the following considerations: (1) findings of different rates of development of various CRs, and (2) findings that experimental manipulations differentially affected various CRs. These manipulations include varying the ISI. Our survey concerned the first point.

Consultation of the original writings of two-factor theorists should support the view that a fundamental aspect of each of the theories involves different rates of acquisition of various types of conditioned responses.

As an example, we present here extracts from the seminal paper of Schlosberg (1937), who proposed that there are

. . . two somewhat different types of learning: (1) simple conditioning, which applies particularly to diffuse, preparatory responses. (2) "Effect" learning, which applies particularly to precise, adaptive responses, and makes greater demands upon the nervous system than does simple conditioning. (p. 379)

The responses to shock may be grouped under two classes, namely, those responses, usually of skeletal muscle, that would remove the member from the locus of the shock, and those reactions of muscle and gland that result from the shock but are not specific to the shocked area. (p. 385)

Regarding the latter, Schlosberg characterized the responses as "emotional, attentional, anticipatory, or preparatory. They 'condition' rather readily" (p. 385). And later, "in general, they prepared the organism for future action. It is these responses that seem to condition most readily and regularly as has been proven in the conditioning of breathing, glandular secretions and galvanic skin responses" (pp. 388-389).

As stated in our paper, the survey simply sought to determine if the distinction made by two-factor theorists regarding differential rates of acquisition was substantiated in the literature, so that their hypotheses could be supported or refuted. The survey and additional analyses presented in this article support the two-stage theories of Pavlovian defensive conditioning. ${ }^{2}$

As noted by one reviewer of the present paper, a full accounting of two-factor theories requires an understanding of how the two processes interact. Thus, for example, the central processes that are expressed as the rapidly acquired CRs may modulate the acquisition and/or expression of the slowly acquired CRs. The reviewer further suggested that this type of interaction could explain the rapid appearance of NM CRs with one trial per session. He noted that with few trials per session, the "optimal" ISI for NM conditioning lengthens (Kehoe et al., 1991; Levinthal, 1973), and longer ISIs are more favorable for the rapidly acquired CRs. Therefore, it is possible that facilitation of fear conditioning with fewer trials per session might influence the rate of development of the NM CR.

\section{OTHER CRITICISMS}

\section{Support for Two-Factor Opposes One-Factor Theories of Conditioning and Does Not \\ Preclude "N" Factors}

Kehoe and Macrae note that:

Lennartz and Weinberger (1992) ended their article by arguing that it would be "wrong-minded" to use any single response to represent classical conditioning and its neural underpinnings. We agree. Nevertheless, their distinction 
between two types of CR implies that two responses might suffice. We disagree. A two-response strategy would be equally wrong-minded, and certainly premature. (p. 3)

We are pleased that Kehoe and Macrae agree with our statement regarding the error of using a single type of CR; we were referring to a prior article by Schreurs (1989). As to the rest of this passage, Kehoe and Macrae attribute a position to us that we did not take, and then argue against this position. Further comment on this would not advance an understanding of the issues at hand. Rather, it would be more helpful for Kehoe and Macrae to explicate their ideas concerning " $n$ " factor theories of Pavlovian defensive conditioning.

\section{The Views of Thompson et al. and Wagner and Brandon}

Kehoe and Macrae refer to the views of Thompson et al. (1987) and Wagner and Brandon (1989) in support of their conclusions. We find this difficult to understand, because both groups of authors support two-factor theories of the type addressed and supported by the survey. ${ }^{3}$

It is clear that Thompson et al. (1987), cited by Kehoe and Macrae, accept the distinction emphasized by Weinberger (1982) between rapidly acquired nonspecific and more slowly acquired specific CRs (see Thompson et al., 1987 , p. 389). Moreover, their formulation is clearly an extension of previous two-factor theories in which nonspecific CRs develop before specific CRs. For example:

We suggest, in the spirit of Konorski (1967), . . . that aversive learning involves two memory trace systems that have distinct neuronal substrates. The first influences the development of the second but once the second memory trace system, the neuronal substrate of the specific response, has developed it can function to some degree independently. (Thompson et al., 1987, p. 394)

Wagner and Brandon (1989), cited by Kehoe and Macrae, set forth a revision of the SOP model. This revision adds a rapidly acquired "emotional" stage of conditioning that precedes the "sensory" stage previously addressed by the SOP model.

\begin{abstract}
AESOP is . . . a dual-representation version of SOP that supposes that stimulus coding involves theoretically separable "emotive" as well as "sensory" components, in line with the distinction made by Konorski (1967). (Wagner \& Brandon, 1989, p. 169)

In particular line with Konorski (1967) and in general sympathy with numerous "two process" theorists (e.g., Mowrer, 1947; Rescorla \& Solomon, 1967; Schlosberg, 1937; Thompson et al., 1986; Weinberger, 1982), we also assume that whereas the prominent behavioral consequence of conditioned (A2) activity of a sensory node is the elicitation of a discrete response, the prominent behavioral consequence of similar conditioned (A2) activity of an emotional node is the diffuse modulation of behavior otherwise initiated. (Wagner \& Brandon, 1989, p. 169)
\end{abstract}

In summary, we can find no grounds for citing the writings of Thompson et al. (1987) and Wagner and Bran- don (1989) as opposing two-factor theories of Pavlovian defensive conditioning.

\section{ASSOCIATIVE AND PERFORMANCE PROCESSES IN NM CONDITIONING Some Neurobiological Considerations}

The larger issue implicitly addressed by Kehoe and Macrae concerns the criteria for establishing an associative process. We agree with them in that an expanded empirical base is necessary for a better understanding of conditioning. We also urge a more detailed and specific discussion of these criteria in the literature.

Additionally, we raise here the question of the extent to which neurobiological findings can clarify the issue of the number and type of associative processes. This is a particularly interesting question not only from a theoretical point of view, but also because many neurobiology researchers have been seeking, and continue to seek, the neural bases of learning. The case of the NM response may be particularly illuminating because its neural substrates have been studied so extensively. Does the high degree of sensitivity of the NM response to the temporal distribution of trials reflect a performance factor or a learning process?

Perhaps the learning process(es) that underlies the NM CR (and its associated eyelid and facial musculature; Thompson et al., 1987) actually mediates very rapidly formed associations regardless of trial density. In that case, the delay in the appearance of NM responses presumably is caused by performance factors that are controlled by trial density. Alternatively, the effect of the distribution of trials may enter into the learning itself.

An extensive series of studies from the laboratories of R. F. Thompson and other researchers has provided considerable evidence that the essential learning process for the NM CR (the NM engram) resides within the cerebellum. What is the rate of development of this engram? Thompson and associates use a large number of training trials so that the first CR generally does not appear until approximately 60-70 trials or more (see, e.g., Berger \& Thompson, 1978). It is of interest that the neurophysiological evidence of the engram does not develop until approximately the same number of trials. In fact, they emphasize the close relationship between the development of the neural changes in the cerebellum and the appearance of the NM CR (see McCormick, Clark, Lavond, \& Thompson, 1982; McCormick \& Thompson, 1984).

Therefore, if the engram for the NM CR has been located, then it is expressed immediately, that is, there is no performance factor that interferes with its behavioral expression. Consequently, trials per session would seem to be directly involved in the learning process(es) rather than affecting the expression of the NM response via performance factors.

It would be interesting to determine the relationship between the rate of development of neurophysiological signs of the engram and the NM response as a function of the 
temporal distribution of training trials. This could help clarify the extent to which learning and performance factors may interact under various trial densities.

Rapid development of CS-specific receptive field plasticity in the auditory cortex has been reported during fear conditioning, as indexed behaviorally by conditioned cardiac deceleration. After only five trials of training, receptive fields have shifted to favor processing of the frequency of the CS versus other acoustic frequencies (Edeline, Pham, \& Weinberger, 1993). The trial density was one trial per 2 min on the average. This demonstrates that a highly specific modification in the processing of information about a frequency that has become associated with shock develops very rapidly despite a high density of training trials. Rapidly acquired neurophysiological changes have been reported in other brain structures during cardiac conditioning, such as in the amygdala (Applegate, Frysinger, Kapp, \& Gallagher, 1982) and prefrontal cortex (Gibbs \& Powell, 1988). If a reliable method for retarding fear conditioning can be found, then it will be possible to determine whether fear conditioning produces the rapid development of specific neuronal plasticity despite retardation of behavioral expression, or if factors that retard expression also retard neural evidence of the formation of associative processes.

\section{THE NEED FOR WITHIN-SUBJECT STUDIES}

In our previous paper, which is under attack by Kehoe and Macrae, we emphasized the importance of withinsubject studies to facilitate the comparison of various response systems and to provide a more integrated view of conditioning processes (Lennartz \& Weinberger, 1992). We reiterate that need here.

Kehoe and Macrae argue that differences in rates of acquisition of the NM CR are a function of the parameters used in a given study. If different classes of response systems have different optimal parameters, then it would be difficult to compare rates of CR development both between and within subjects. For example, we did note that the heart rate CR was acquired more slowly at the ISI of $250 \mathrm{msec}$, which is generally considered near optimal for NM conditioning (see Table 1 of Lennartz \& Weinberger, 1992). However, Powell and Levine-Bryce (1988) found that a 500-msec ISI was sufficient for both robust conditioning of the NM response and a beat-by-beat analysis of heart rate. This eliminates the need to assess heart rate only on test trials. In their study, heart rate conditioning developed significantly faster than did the NM CR. Sixty trials per day were used; thus, the NM CR was undoubtedly retarded, so conclusions about different learning rates must be limited. However, Powell and LevineBryce do demonstrate the use of parameters that support both heart rate and NM conditioned responses. The problem of requiring a very brief (e.g., $250 \mathrm{msec}$ ) ISI for NM conditioning, which is too brief for cardiac conditioning, for example, becomes even more inconsequential when the NM data of Levinthal (1973) are considered: as the number of trials per session is reduced from 20 to 1 , the superiority of the 250-msec ISI decreases, and at 1 trial per day the 1,250 -msec ISI is actually superior. In addition, in a trace paradigm with 1 trial per day, Kehoe et al. (1991) demonstrated effective conditioning with an ISI of 3,200 msec. This should be sufficient to assess heart rate changes and probably other responses that were included in our survey.

Thus, a study in which various CRs are measured under conditions of a few, or even one, trial(s) per day is quite feasible and, we believe, would be the most direct method of answering the question of whether the bimodality of acquisition rates is maintained under such circumstances. We suggest that researchers who routinely study the NM CR should determine the relative rates of development of this and several other conditioned responses by using paradigms that not only support both types of CR, but also are optimal for NM conditioning.

\section{CONCLUSIONS}

In conclusion, Kehoe and Macrae have advanced consideration of theoretical issues concerning associative processes in Pavlovian defensive conditioning by emphasizing the importance of massed versus distributed training for the NM CR. They have also corrected the potential misinterpretation of the average value of trials to the first $\mathrm{CR}$ for this $\mathrm{CR}$ given in our survey. However, they have not shown that the NM CR is acquired as rapidly as are responses of the class of rapidly developing "nonspecific" CRs. Therefore, there is no compelling basis for disregarding the overall findings of our survey, which support two-factor theories of Pavlovian defensive conditioning. Moreover, we once again urge further within-subject studies of multiple response systems to provide an appropriate means for resolving many remaining issues. Finally, we strongly suggest that neurobiological studies of Pavlovian defensive conditioning be considered in closer relationship to behavioral studies in order to clarify the issue of underlying associative processes.

\section{REFERENCES}

Annau, Z., \& Kamin, L. J. (1961). The conditioned emotional response as a function of intensity of the US. Journal of Comparative \& Physiological Psychology, 54, 428-432.

Applegate, C. D., Frysinger, R. C., Kapp, B. S., \& Gallagher, M. (1982). Multiple unit activity recorded from amygdala central nucleus during Pavlovian heart rate conditioning in rabbit. Brain Research. 238, 457-462.

BARNES, G. W. (1956). Conditioned stimulus intensity and temporal factors in spaced-trial classical conditioning. Journal of Experimental Psychology, 51, 192-198.

Berger, T. W., \& Thompson, R. F. (1978). Neuronal plasticity in the limbic system during classical conditioning of the rabbit nictitating membrane response: I. The hippocampus. Brain Research, 145, 323-346.

Burdick, C. K., \& James, J. P. (1973), Effects of a backward conditioning procedure following acquisition on extinction of conditioned suppression. Animal Learning \& Behavior, 1, 137-139.

Edeline, J.-M., Pham, P., \& Weinberger, N. M. (1993). Rapid development of learning-induced receptive field plasticity in the auditory cortex. Behavioral Neuroscience, 107, 539-551

Gibis, C. M., \& Powell, D. A. (1988). Neuronal correlates of classi- 
cally conditioned bradycardia in the rabbit: Studies of the medial prefrontal cortex. Brain Research, 442, 86-96.

GRAY, T. (1979). Sudden, rapid acquisition of conditioned suppression (CER). Animal Learning \& Behavior, 7, 351-354.

Gustafson, J. W., Lindsky, T. I., \& Schwartzbaum, J. S. (1975). Effects of hippocampal stimulation on acquisition, extinction, and generalization of conditioned suppression in the rat. Journal of Comparative \& Physiological Psychology, 89, 1136-1148.

Harvey, J. A., Gormezano, I., \& COOl-Hauser, V. A. (1985). Relationship between heterosynaptic reflex facilitation and acquisition of the nictitating membrane response in control and scopolamine-injected rabbits. Journal of Neuroscience, 5, 596-602.

IsON, J. R., \& LEONARD, D. W. (1971). Effects of auditory stimuli on the amplitude of the nictitating membrane reflex of the rabbit (Oryctolagus cuniculus). Joumal of Comparative \& Physiological Psychology, 75, 157-164.

James, J. P., Shangi, L., Pangman, C., \& Mostoway, W. (1973). The role of number and spacing of CS-US pairings in conditioned suppression. Animal Learning \& Behavior, 1, 140-144.

KAmIN, L. J. (1961). Apparent adaptation effects in the acquisition of a conditioned emotional response. Canadian Journal of Psychology, 15, 176-188.

KAMIN, L. J. (1963). Backward conditioning and the conditioned emotional response. Journal of Comparative \& Physiological Psychology, 56, 517-519.

Kehoe, E. J., Cool, V., \& Gormezano, I. (1991). Trace conditioning of the rabbit's nictitating membrane response as a function of CSUS interstimulus interval and trials per session. Learning \& Motivation, 22, 269-290.

Kehoe, E. J., \& Gormezano, I. (1974). Effects of trials per session on conditioning of the rabbit's nictitating membrane response. Bulletin of the Psychonomic Society, 4, 434-436.

Kehoe, E. J., \& MACrae, M. (1994). Classical conditioning of the rabbit nictitating membrane response can be fast or slow: Implications for Lennartz and Weinberger's (1992) two-factor theory. Psychobiology, 22,14 .

Kimmel, H. D., Kimmel, E. B., \& Silver, A. I. (1969). The effect of UCS intensity in classical and avoidance GSR conditioning. Conditional Reflex, 4, 32-51

KoNORSKI, J. (1967). Integrative activity of the brain: An interdisciplinary approach. Chicago: University of Chicago Press.

LENNARTZ, R. C., \& WEINBERGER, N. M. (1992). Analysis of response systems in Pavlovian conditioning reveals rapidly versus slowly acquired conditioned responses: Support for two factors, implications for behavior and neurobiology. Psychobiology, 20, 93-119.

Levinthal, C. F. (1973). The CS-US interval function in rabbit nictitating membrane response conditioning: Single vs. multiple trials per conditioning session. Learning \& Motivation, 4, 259-267.

Levinthal, C. F., \& PaPsdorf, J. D. (1970). The classically conditioned nictitating membrane response: The CS-US interval function with one trial per day. Psychonomic Science, 21, 296-297.

Levinthal, C. F., Tartell, R. H., Margolin, C. M., \& Fishman, H. (1985). The CS-US interval (ISI) function in rabbit nictitating membrane response conditioning with very long intertrial intervals. Animal Learning \& Behavior, 13, 228-232.

LOGAN, M. S., \& SCHNUR, P. (1976). The effects of nonreinforced and randomly reinforced stimulus preexposure on conditioned suppression in rats. Bulletin of the Psychonomic Society, 8, 336-338.

MaCkINTOSH, N. J. (1974). The psychology of animal learning. London: Academic Press.

MARTIN, I., \& LEVEY, A. B. (1966). Latency of the eyelid UCR during conditioning. Life Sciences, 5, 17-26.

MarTin, I., \& LeVEy, A. B. (1969). The genesis of the classical conditioned response (International Series of Monographs in Experimental Psychology, Vol. 8). London: Pergamon.

McCormick, D. A., ClakK, G. A., Lavond, D. G., \& Thompson, R. F. (1982). Initial localization of the memory trace for a basic form of learning. Proceedings of the National Academy of Science, 79, $2731-2735$.
McCormick, D. A., \& Thompson, R. F. (1984). Neuronal responses of the rabbit cerebellum during acquisition and performance of a classically conditioned nictitating membrane-eyelid response. Journal of Neuroscience, 4, 2811-2822.

Mowrer, O. H. (1947). On the dual nature of learning: A reinterpretation of "conditioning" and "problem-solving." Harvard Educational Review, 17, 102-148.

Powell, D. A., \& Levine-Bryce, D. (1988). A comparison of two model systems of associative learning: Heart rate and eyeblink conditioning in the rabbit. Psychophysiology, 25, 672-682.

RANDICH, A., \& MAIXNER, W. (1981). Acquisition of conditioned suppression and responsivity to thermal stimulation in spontaneously hypertensive, renal hypertensive and normotensive rats. Physiology \& Behavior, 27, 585-590.

Rescorla, R. A., \& Solomon, R. L. (1967). Two-process learning theory: Relationships between Pavlovian conditioning and instrumental learning. Psychological Review, 74, 151-182.

RIESS, D., \& FARRAR, C. H. (1973). UCS duration and conditioned suppression: Acquisition and extinction between-groups and terminal performance within-subjects. Learning \& Motivation, 4, 366-373.

Salafia, W. R., Daston, A. P., \& Martino, L. J. (1976). Conditioning of the rabbit (Oryctolagus cuniculus) nictitating membrane response as a function of trials per session and ISI with a short intersession interval. Bulletin of the Psychonomic Society, 7, 343-344.

Salafia, W. R., Terry, W. S., \& Daston, A. P. (1975). Conditioning of the rabbit (Oryctolagus cuniculus) nictitating membrane response as a function of trials per session, ISI, and ITI. Bulletin of the Psychonomic Society, 6, 505-508.

SCHLOSBERG, H. (1937). The relationship between success and the laws of conditioning. Psychological Review, 44, 379-394.

SCHNEIDERMAN, N. (1972). Response system divergencies in aversive classical conditioning. In A. H. Black \& W. F. Prokasy (Eds.), Classical conditioning II: Current theory and research (pp. 341-376). New York: Appleton-Century-Crofts.

Schreurs, B. G. (1989). Classical conditioning of model systems: A behavioral review. Psychobiology, 17, 145-155.

Thompson, R. F., Donegan, N. H., Clark, G. A., Lavond, D. G., Lincoln, J. S., Madden, J., IV, Mamounas, L. A., Mauk, M. D., \& McCORMICK, D. A. (1987). Neuronal substrates of discrete, defensive conditioned reflexes, conditioned fear states, and their interactions in the rabbit. In I. Gormezano, W. F. Prokasy, \& R. F. Thompson (Eds.), Classical conditioning (pp. 371-399). Hillsdale, NJ: Erlbaum.

WAGNer, A. R., \& Brandon, S. E. (1989). Evolution of a structured connectionist model of Pavlovian conditioning (AESOP). In S. B. Klein \& R. R. Mowrer (Eds.), Contemporary learning theories: Pavlovian conditioning and the status of traditional learning theory (pp. 149190). Hillsdale, NJ: Erlbaum.

WEINBERGER, N. M. (1982). Effects of conditioned arousal on the auditory system. In A. L. Beckman (Ed.), The neural basis of behavior (pp. 63-91). New York: Spectrum.

Weisz, D. J., HARDEN, D. G., \& XIANG, Z. (1992). Effects of amygdala lesions on reflex facilitation and conditioned response acquisition during nictitating membrane response conditioning in rabbit. $B e$ havioral Neuroscience, 106, 262-273.

WeISZ, D. J., \& MCINERNEY, J. (1990). An associative process maintains reflex facilitation of the unconditioned nictitating membrane response during the early stages of training. Behavioral Neuroscience, 104, 21-27.

Young, R. A., Cegavske, C. F., \& Thompson, R. F. (1976). Toneinduced changes in excitability of abducens motoneurons and of the reflex path of nictitating membrane response in rabbit (Oryctolagus cuniculus). Journal of Comparative \& Physiological Psychology, 90 , 424-434.

\section{NOTES}

1. Data on changes in the UR during human eyeblink conditioning, which are largely ignored by modern investigators, have been discussed in detail by Martin and Levey (1969). For example, there are decreases 
in the UR latency before the first eyeblink CR appears (Martin \& Levey, 1966). These decreases correlate with the level of conditioning; thus, the subjects that demonstrate better conditioning (in terms of percent CRs) exhibit more rapidly acquired decreases in UR latency.

2. Another variable that could be relevant in distinguishing between the two types of responses is absolute time from the start of training. That is, the more quickly acquired responses may require less time to develop than would the slowly acquired responses. A further discussion of this particular factor is beyond the scope of this paper.
3. The two reviewers of the present paper disagreed as to whether or not Kehoe and Macrae were contrasting our view of two-factor theories with those of Thompson et al. (1987) and Wagner and Brandon (1989). Our comments here are intended to highlight the similarities of our views with those of these authors.

(Manuscript received July 22, 1993;

revision accepted for publication October 5, 1993.) 